\title{
Application of Simplified Neutral Point Clamped Multilevel Converter in a Small Wind Turbine
}

\author{
Pawel Mlodzikowski (Doctoral Student, Warsaw University of Technology - WUT), \\ Adam Milczarek (Doctoral Student, WUT), Mariusz Malinowski (Leading Researcher, WUT)
}

\begin{abstract}
In low power distributed generation systems low cost together with the energy quality requirements are a key element. It is known that quality of voltage waveforms generated from multilevel converters is better in comparison with those from two-level. Due to advancements in power electronics and microcontrollers, multilevel converters are being built with the use of integrated power modules thus this type of converters are getting more compact in size. This paper investigates performance of a derivation from the most popular multilevel topology - a neutral point clamped converter (NPC). Applying the idea for simplifying the topology by reducing the number of switches (what came from drives) this NPC converter is capable of bidirectional AC/DC/AC operation. For the AC/DC part two schemes are tested: Direct Torque Control Space Vector Modulated and Field Oriented Control but for the DC/AC part a control scheme utilizing the proportional-resonant controller was chosen. Laboratory setup was based on a permanent magnet synchronous generator with control and acquisition completed with the help of dSpace 1005 control box. Experimental verification shows that system operates properly.
\end{abstract}

Keywords - AC-DC power converters; Power conversion harmonics; Wind energy generation; Bidirectional power flow.

\section{INTRODUCTION}

Cost optimization of a power converter based on the idea of replacing one of the semiconductor branches with a split capacitor bank and connecting a phase wire to its middleproposed in [1]. It gives lower number of switching devices comparing to a classical 2-level AC-DC-AC converter which corresponds to reduced number of control channels, IGBT driver circuits etc. Despite above advantages of a 2-level simplified converter for obtaining sinusoidal current there is a necessity to maintain higher DC voltage, that gives higher voltage stress of converter semiconductor devices [2]-[4]. This problem can be solved by application of a 3L-NPC power modules with clamping diodes. New compact devices make it easier to improve the topology with a split capacitor in DClink that is shown in Fig. 1 [5], [6].

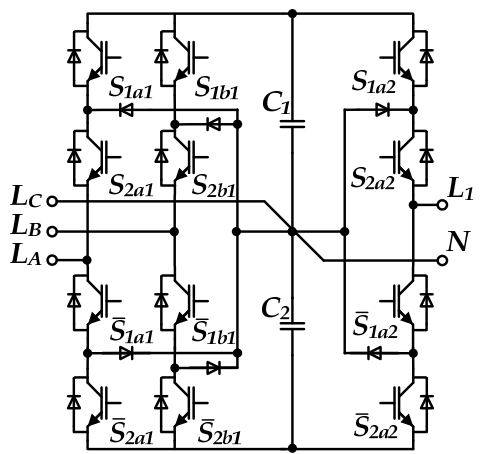

Fig. 1. Simplified AC/DC/AC multilevel NPC converter.
Content of the paper is the following. The second section describes the chosen modulation algorithms for the AC/DC/AC. The third section describes the two control methods implemented for the AC/DC part of converter connecting to PMSG and a proposed control utilizing a proportional-resonant (PR) controller for the grid side DC/AC converter. Section four is dedicated to experimental results. The last closing section is left for conclusion.

\section{Modulation}

Modulation for simplified back-to-back converters is realized separately for the $\mathrm{DC} / \mathrm{AC}$ and $\mathrm{AC} / \mathrm{DC}$ stage with the use of switching states depicted in Fig.2 and Fig.3. It can be utilized using a universal concept of time-domain duty-cycle computation technique for single-phase multilevel converters described as one dimensional modulation (1DM) technique presented in Fig. 2 [7].

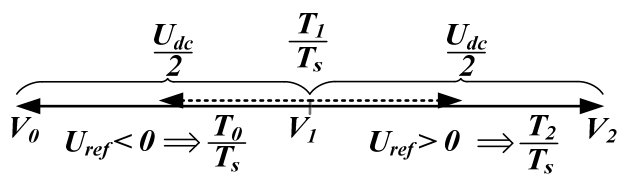

Fig. 2. Vector plane for 1-DM modulation of single-phase DC/AC converter

For the single phase converter calculating durations of vectors are described as:

$$
\begin{gathered}
T_{2}=\frac{\left|\underline{U}_{r e f}\right|}{0.5 U_{D C}} T_{s} ; \quad T_{1}=T_{s}-T_{2} ; \quad \operatorname{Re}\left(\underline{U}_{r e f}\right) \geq 0 \quad \text { and } \\
T_{0}=\frac{\left|\underline{U}_{r e f}\right|}{0.5 U_{D C}} T_{s} ; \quad T_{1}=T_{s}-T_{0} ; \quad \operatorname{Re}\left(\underline{U}_{r e f}\right)<0
\end{gathered}
$$

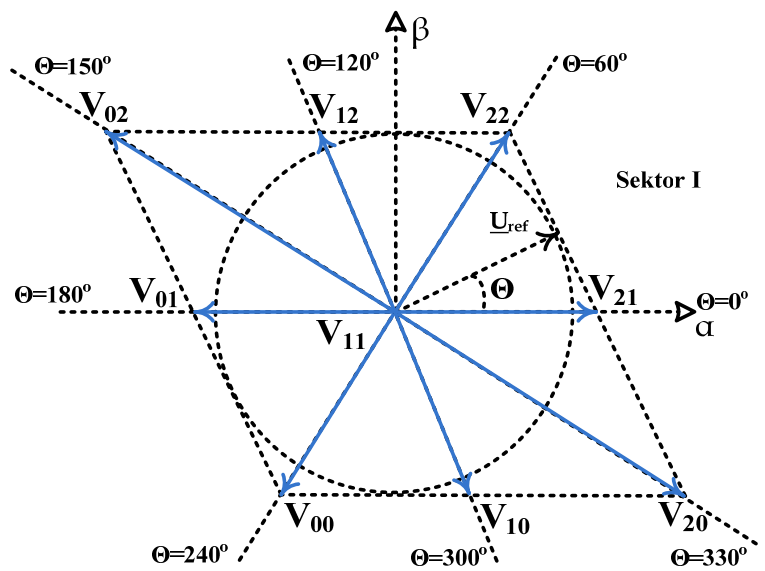

Fig. 3. Possible voltage vectors generated by the simplified three-phase $\mathrm{DC} / \mathrm{AC}$ converter. 


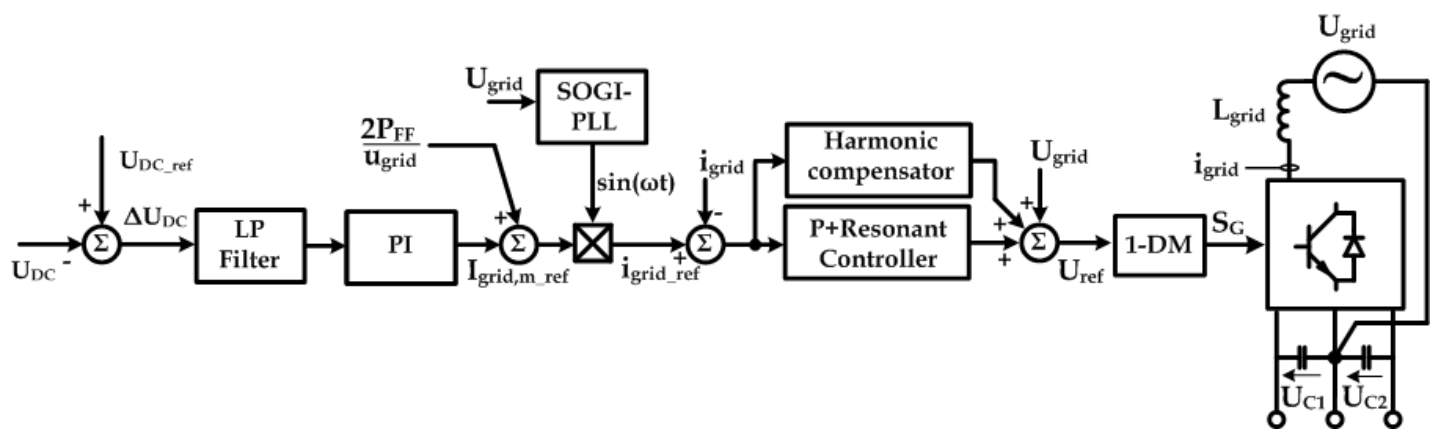

Fig. 4. Single-phase DC/AC converter control scheme.

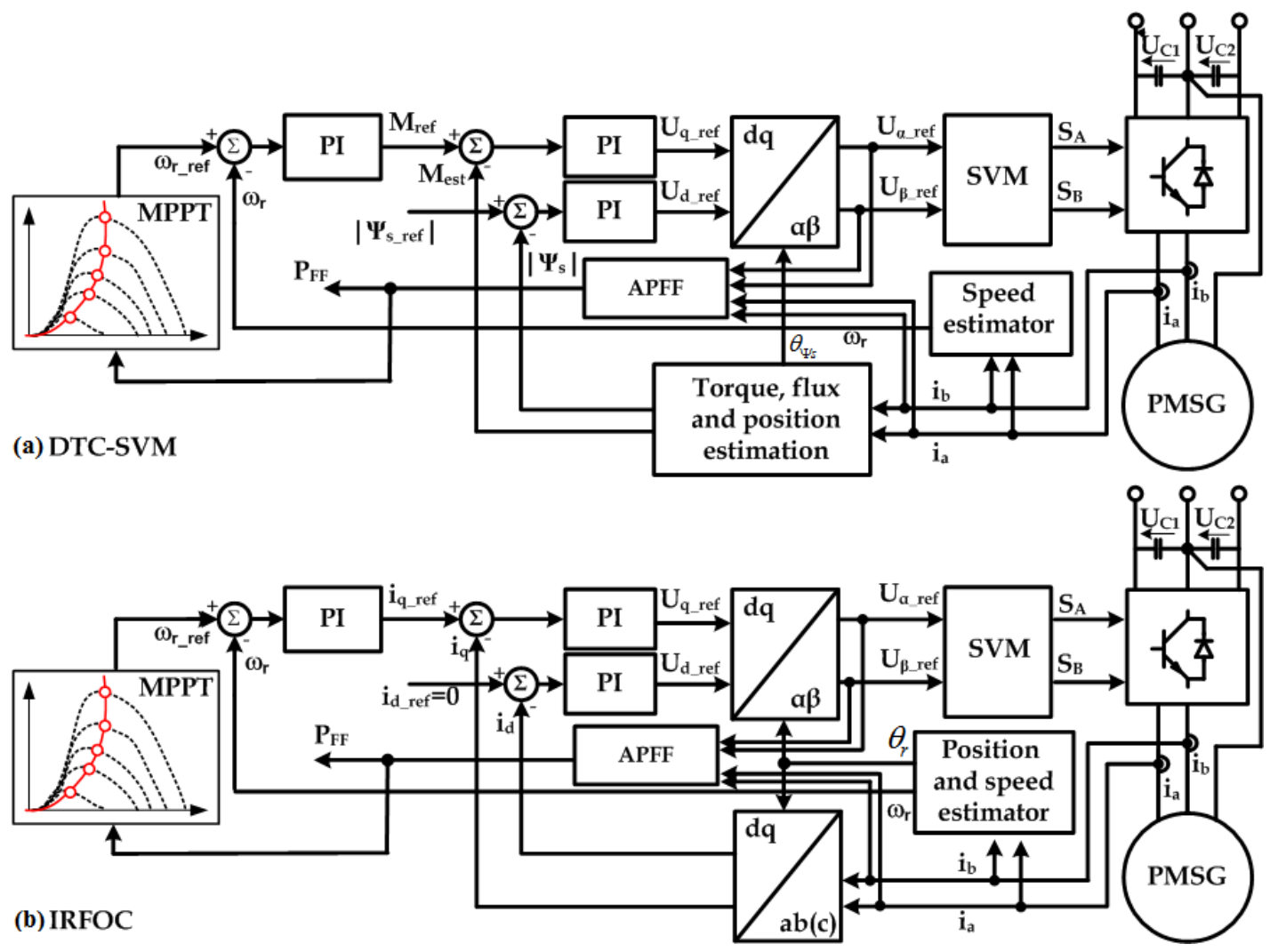

Fig. 5. Three phase AC/DC converter control schemes of DTC-SVM (a) and IRFOC (b).

Fig.3 shows graphic representation of space vector $\alpha \beta$ voltage plane with nine possible to obtain voltage vectors of three-phase three-level simplified converter. It gives eight active vectors $\left(V_{21}, V_{22}, V_{12}, V_{02}, V_{01}, V_{00}, V_{10}, V_{20},\right)$ and one zero vector $\left(V_{l 1}\right)$. Switching times for the Sector I $\left(0^{\circ} \leq \theta<60^{\circ}\right)$ can be computed as:

$$
\begin{gathered}
T_{21}=\frac{\sqrt{6} U_{\alpha}}{U_{D C}} T_{s}-\frac{\sqrt{2} U_{\beta}}{U_{D C}} T_{s} \\
T_{22}=\frac{2 \sqrt{2} U_{\beta}}{U_{D C}} T_{s} \\
T_{11}=T_{s}-T_{21}-T_{22}
\end{gathered}
$$

\section{CONTROL}

\section{A. Control of Single-phase Grid Converter}

Fig. 4 presents control of single-phase grid side converter based on PR controller firstly proposed in [8]. The $\Delta U_{D C}$ voltage is an error calculated by subtraction of measured DClink voltage $\left(U_{D C}\right)$ from $\mathrm{DC}$ voltage reference $U_{D C \_r e f}$. Error filtered by a low pass filter with a $f_{\text {cut off }}=30 \mathrm{~Hz}$ is entering a PI controller. Output value from the PI block with addiction of the active power feed-forward signal (APFF) is then multiplied by a sine function of the grid voltage angle, which is calculated by a SOGI-PLL. Resulting outcome becomes reference value for the PR current controller and parallel harmonic compensator block. Resonant part of mentioned PR controller is tuned at the fundamental grid frequency $\omega$ for which the highest gain is obtained but harmonic compensator contains resonant part tuned to specific high order harmonics e.g. $5^{\text {th }}, 7^{\text {th }}[9]-[10]$. 


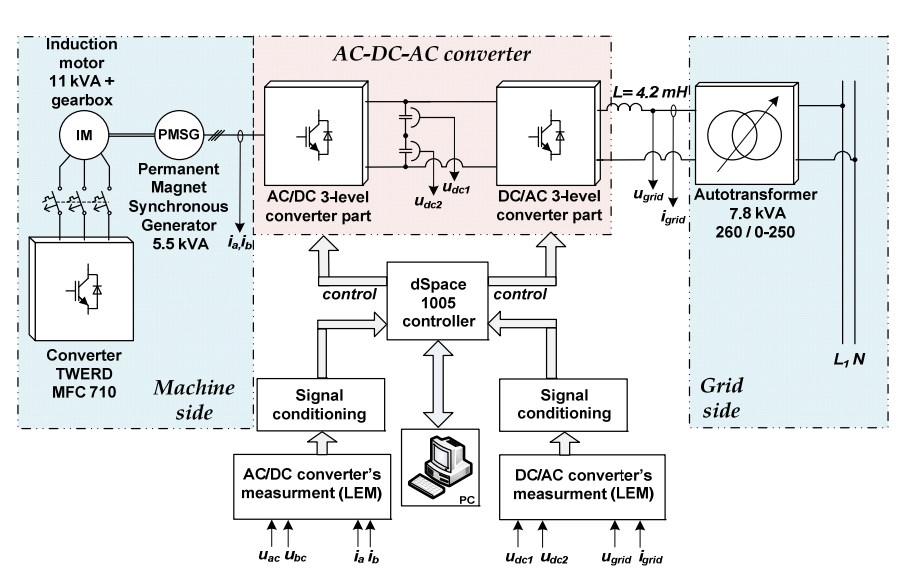

Fig. 6. Block scheme of laboratory setup.

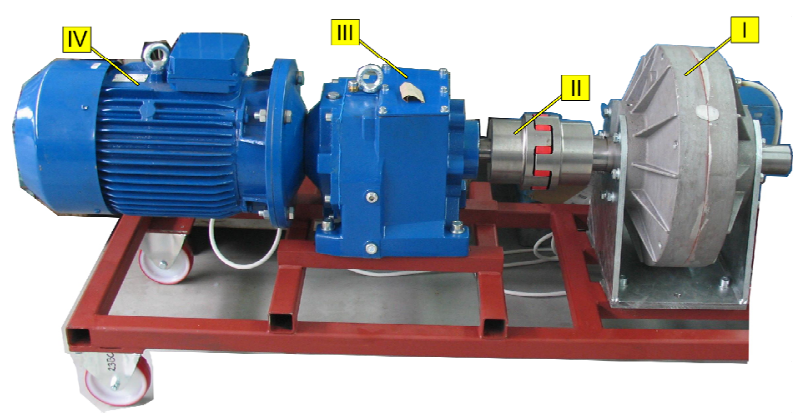

Fig. 7. PMSG based wind turbine laboratory model: I - low speed PMSG, II - clutch, III - gearbox, IV - high speed induction motor.

\section{B. Control of Three-phase Generator Side Converter}

For controlling the machine side converter two popular control strategies are investigated. The first shown in Fig. 5(a) is the Direct Torque Control with Space Vector Modulation (DTC-SVM) [11]. It consists of a torque $M$, stator flux $\Psi_{s}$ and speed $\omega$ control loops. Reference value for torque is provided by an outer PI speed controller. Reference value of flux is subtracted from estimated and the error is an input for a PI flux controller. From outputs of PI torque and flux controllers converter voltage in $d q$ coordinates is (after transformation to stationary coordinate system) a reference for modulation algorithm based on space vector representation (SVM) shown in Fig. 3.

Second viable control scheme is based on Indirect Rotor Field Oriented Control - IRFOC, Fig. 5(b). In this scheme reference speed denoted as $\omega_{r_{-} \text {ref }}$ is compared with estimated angular speed $\omega_{r}$. Obtained error is an input for a PI speed controller that calculates the reference for the current $i_{q_{-}}$ref (responsible for electromagnetic torque). Reference current $i_{d_{-} \text {ref }}$ is set to be zero. PI current controllers set voltage values of $U_{d_{-} \text {ref }}$ and $U_{q_{-} \text {ref, }}$, which after transformation to stationary $\alpha \beta$ coordinate system are needed for space vector modulation (SVM). Active power feed forward (APFF) is calculated in both schemes Fig. 5(a) and Fig. 5(b) to improve dynamic performance and stabilize dc-link. APFF is delivered to the DC/AC converter as shown in Fig.4 [12]-[15].

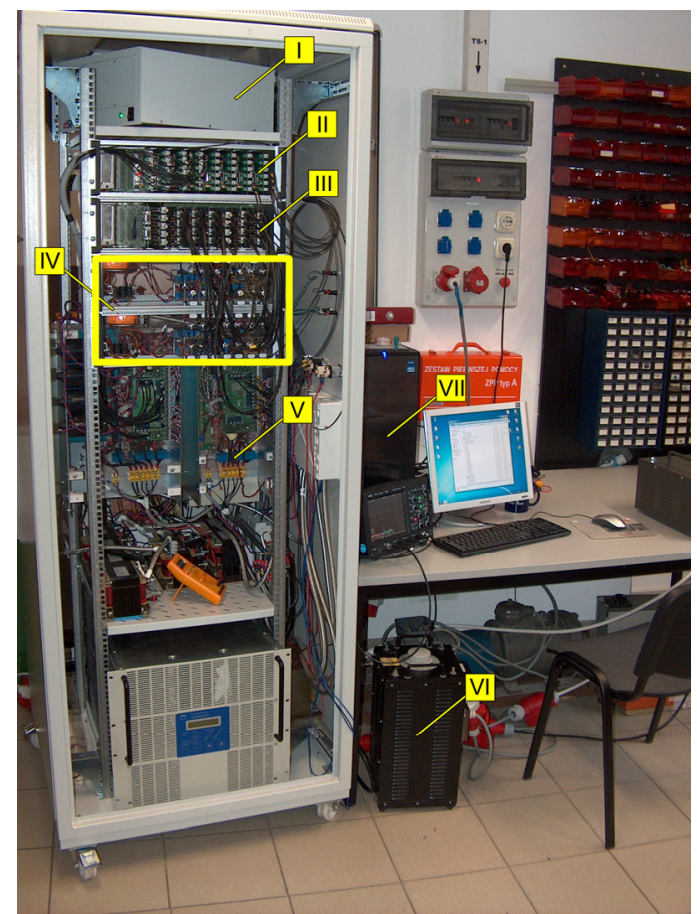

Fig. 8. Laboratory control setup: I - dSpace 1005 system, II - PWM control signal interface, III - signal conditioning, IV - LEM based measure circuits, $\mathrm{V}-\mathrm{AC} / \mathrm{DC} / \mathrm{AC}$ converter, VI - autotransformer, VII - PC class computer.

\section{EXPERIMENTAL RESULTS}

General idea of the laboratory setup of a simplified multilevel AC/DC/AC converter for SWT is presented in Fig.6 and Fig. 8.

Laboratory verification was conducted using a $5.5 \mathrm{~kW}$ Permanent Magnet Synchronous Generator with 20 pole pairs and nominal speed of $150 \mathrm{rpm}$ (Fig. 7). Generator was connected by a gearbox with an $11 \mathrm{~kW}$ Induction Motor controlled by a commercial industrial inverter. Chosen experimental results are shown in Fig.9-18 and a list of the laboratory setup parameters is given in Table 1. In Fig.9 a steady state of the single-phase DC/AC converter at grid connected mode of operation is shown. Stand-alone operation at step-change of the load is presented in Fig. 10. Fig.11 and Fig. 14 are also from steady state operation but for the threephase AC/DC converter using two investigated control methods (DTC-SVM, IFOC). Next oscillograms are showing dynamic responses for step increase and decrease of reference speed, in case of DTC-SVM (Fig. 12- 13), and IRFOC (Fig. 15-16). In both cases dynamic behavior of the system is satisfying. Operation of IRFOC without and with active power feed-forward (APFF) is shown in Fig. 17-20.

TABLE I

PARAMETERS OF THE LABORATORY SETUP

\begin{tabular}{|c|c|c|}
\hline Nominal power & $5.5 \mathrm{~kW}$ & \multirow{3}{*}{ PMSG } \\
\hline Pole pairs & 20 & \\
\hline Nominal speed & $150 \mathrm{rpm}$ & \\
\hline Nominal voltage & $3 \times 380 \mathrm{~V}$ & \\
\hline Phase winding resistance & $4.4 \mathrm{ohm}$ & \multirow{3}{*}{\begin{tabular}{c}
\multirow{2}{*}{ AC/DC/AC } \\
Converter
\end{tabular}} \\
\hline Phase inductance & $30 \mathrm{mH}$ & \\
\hline Summary dc-link & $1.5 \mu \mathrm{F}$ & \\
\hline Grid side filter inductance & $4.2 \mathrm{mH}$ & \\
\hline Control system & $\mathrm{dSpace} 1005$ & \\
\hline Switching frequency & $8 \mathrm{kHz}$ &
\end{tabular}


A. DC/AC Converter Operation

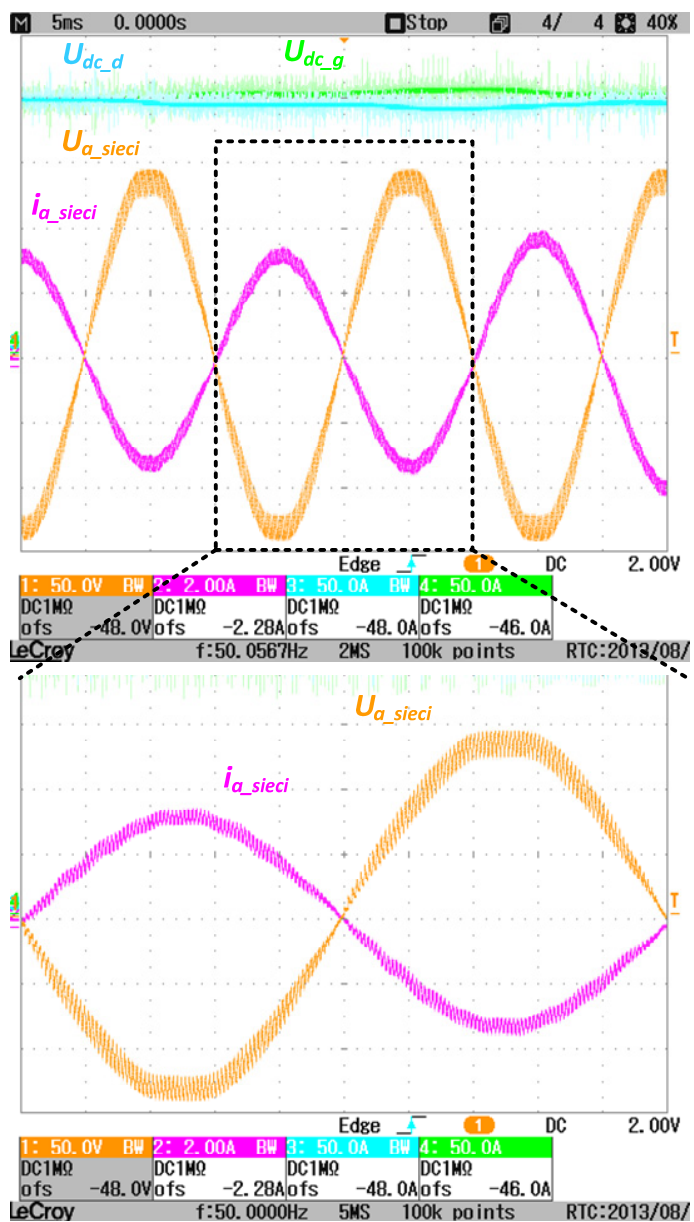

Fig. 9. Steady state of single-phase DC/AC part of converter at grid connected mode of operation. From top: voltage on upper capacitor $\left(U_{d c}\right)$, voltage on lower capacitor $\left(U_{d c \_}\right)$, grid voltage $\left(U_{a_{-} \text {sieci }}\right)$ and grid current $\left(i_{a_{-} \text {sieci }}\right)$.

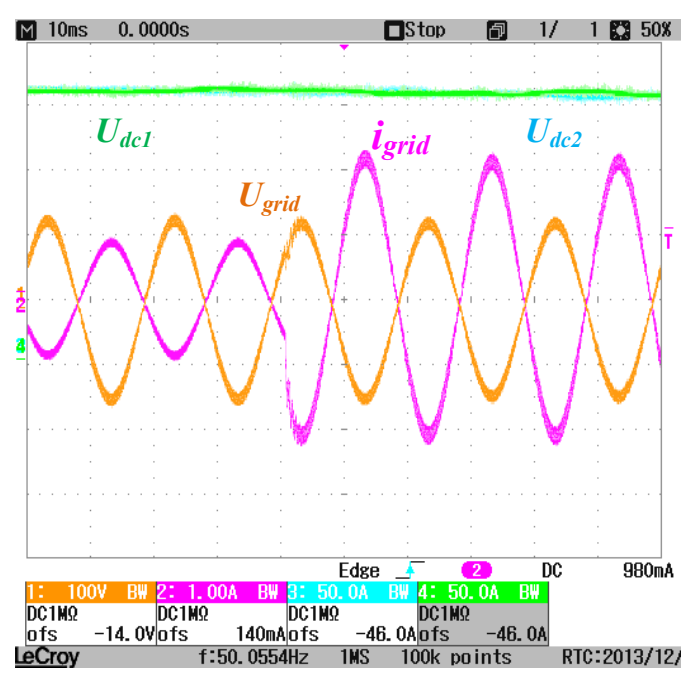

Fig. 10. Step-change of the load for single-phase DC/AC part of converter at stand-alone mode of operation. From top: voltage on upper capacitor $\left(U_{d c l}\right)$, voltage on lower capacitor $\left(U_{d c 2}\right)$, grid voltage $\left(U_{\text {grid }}\right)$ and inverted grid current $\left(i_{\text {grid }}\right)$.

\section{B. AC/DC Control Operation with DTC-SVM}

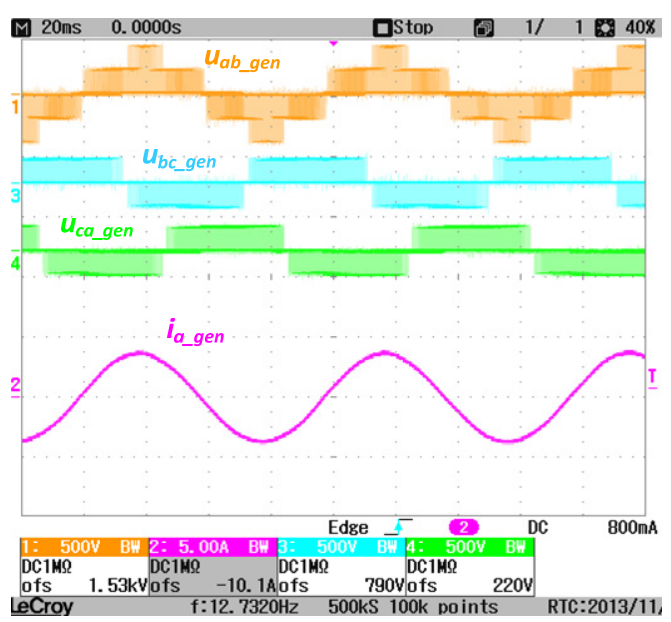

Fig. 11. Steady state of three-phase AC/DC part of converter. From top: phase to phase voltages of converter $\left(u_{a b \text { _gen, }}, u_{b c \text { _gen }}, u_{c a \text { _gen }}\right)$ and generator phase current $i_{a}$.

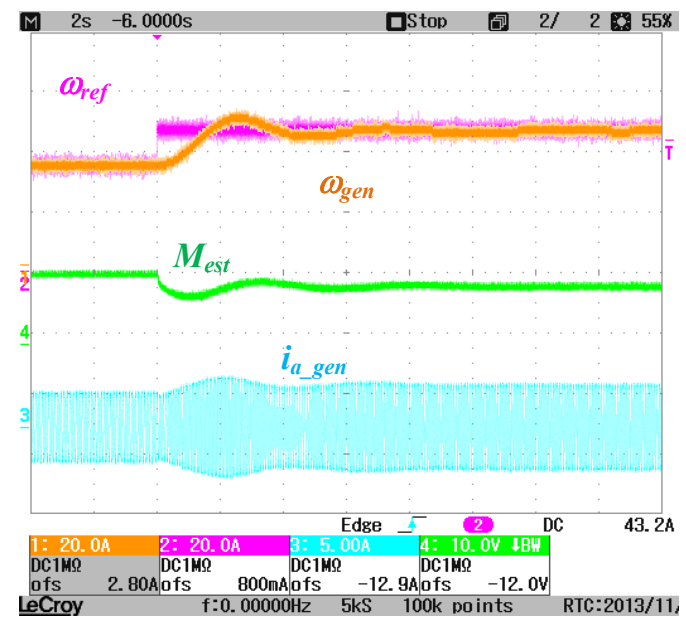

Fig. 12. Response for step change of speed. From top: reference speed $\left(\omega_{r e f}\right)$, measured speed $\left(\omega_{\text {gen }}\right)$, estimated torque $\left(M_{\text {est }}\right)$, phase current $\left(i_{\text {__gen }}\right)$.

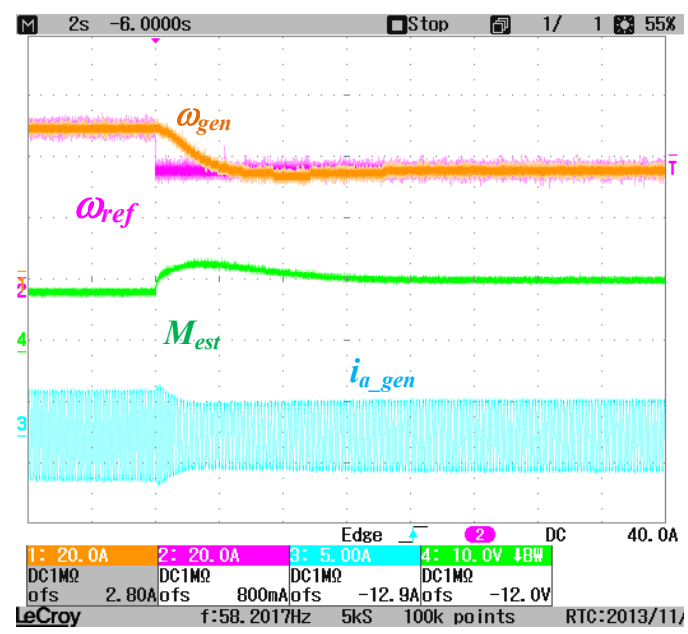

Fig. 13. Response for step change of speed. From top: reference speed $\left(\omega_{\text {ref }}\right)$, measured speed $\left(\omega_{\text {gen }}\right)$, estimated torque $\left(M_{\text {est }}\right)$, phase current $\left(i_{\text {agen }}\right)$. 


\section{AC/DC Control Operation with IRFOC}

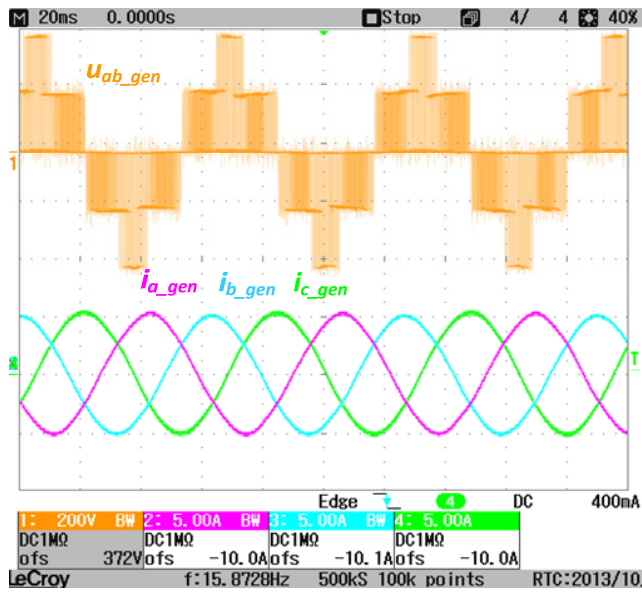

Fig. 14. Steady state of AC-DC part of converter. From top: phase to phase voltage of converter $\left(u_{a b \_g e n}\right)$ and generator phase currents $\left(i_{a_{-} \text {gen }}, i_{b_{-} \text {gen }}, i_{c_{\_} \text {gen }}\right)$.

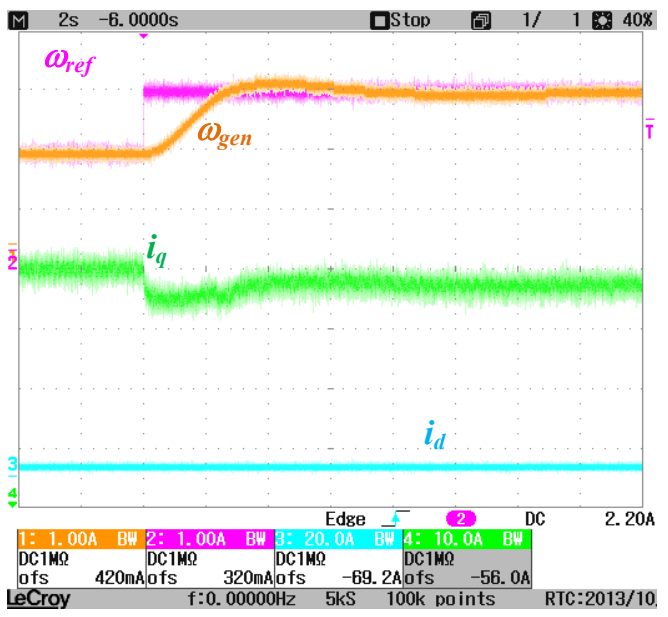

Fig. 15. Response for step change of speed. From top: speed reference $\left(\omega_{\text {ref }}\right)$, estimated speed $\left(\omega_{\text {gen }}\right)$, current in q-axis $\left(i_{q}\right)$, current in d-axis $\left(i_{d}\right)$.

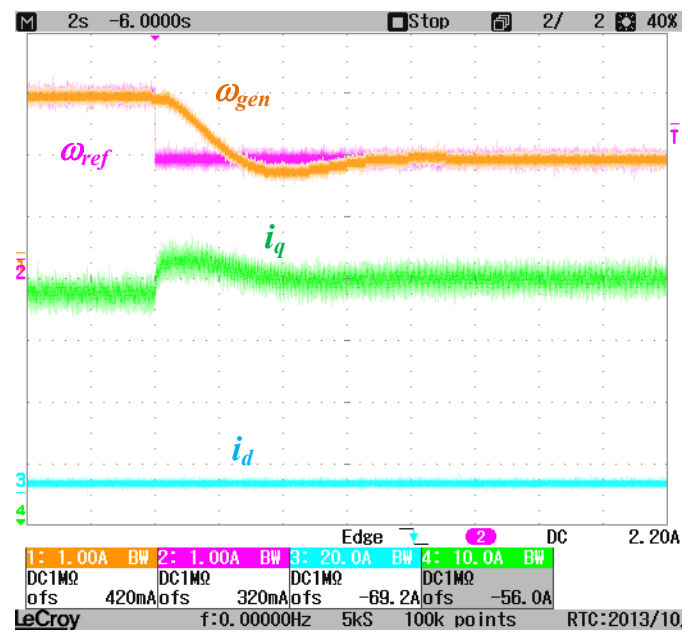

Fig. 16. Response for step change of speed. From top: reference speed $\left(\omega_{\text {ref }}\right)$, estimated speed $\left(\omega_{\text {gen }}\right)$, current in q-axis $\left(i_{q}\right)$, current in d-axis $\left(i_{d}\right)$.
D. DC/AC Control Operation with APFF

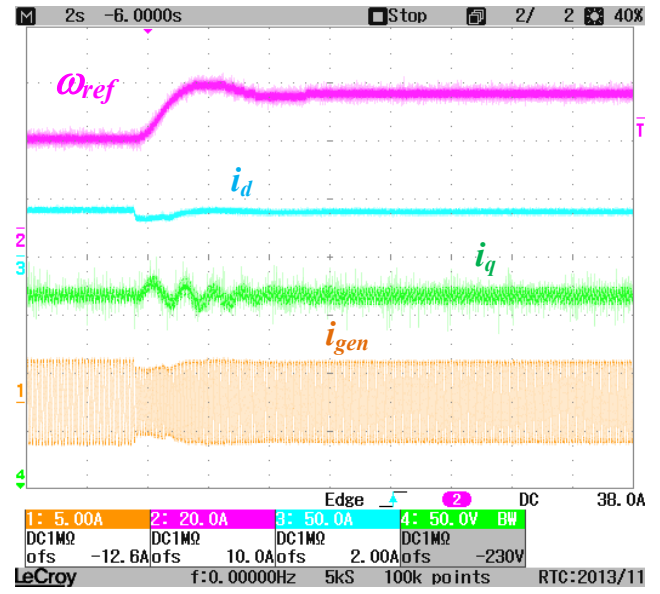

Fig. 17. Response for step change of speed without APFF. From top: estimated speed $\left(\omega_{\text {gen }}\right)$, current in d-axis $\left(i_{d}\right)$, current in q-axis $\left(i_{q}\right)$, generator current $\left(i_{\text {gen }}\right)$.

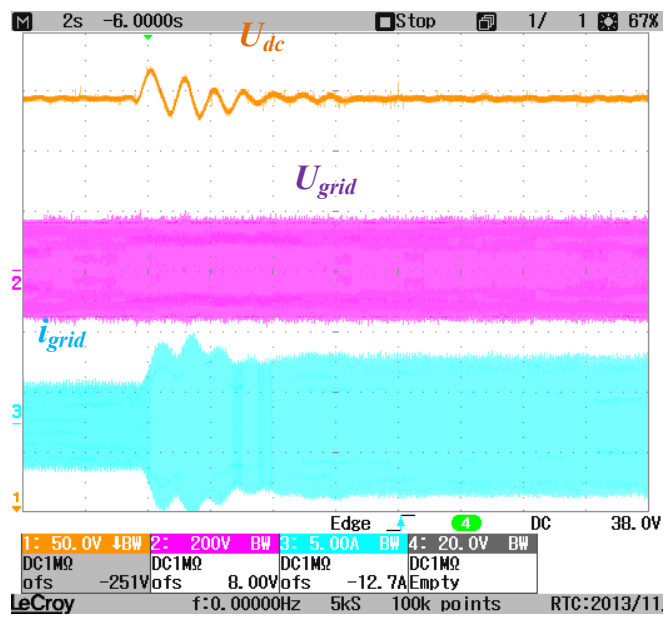

Fig. 18. Response for step change of speed without APFF. From top: dc-link voltage $\left(U_{d c}\right)$, grid voltage $\left(U_{\text {grid }}\right)$, grid current $\left(i_{\text {grid }}\right)$.

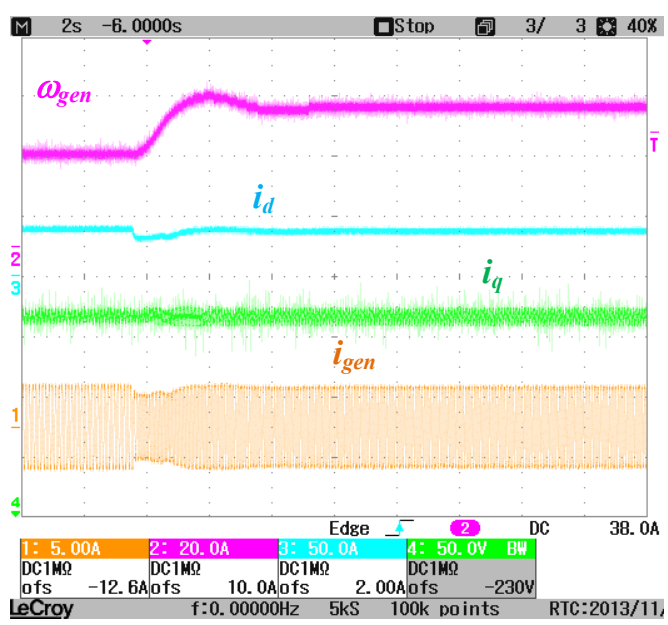

Fig. 19. Response for step change of speed with APFF. From top: estimated speed $\left(\omega_{\text {gen }}\right)$, current in d-axis $\left(i_{d}\right)$, current in q-axis $\left(i_{q}\right)$, generator current $\left(i_{\text {gen }}\right)$. 


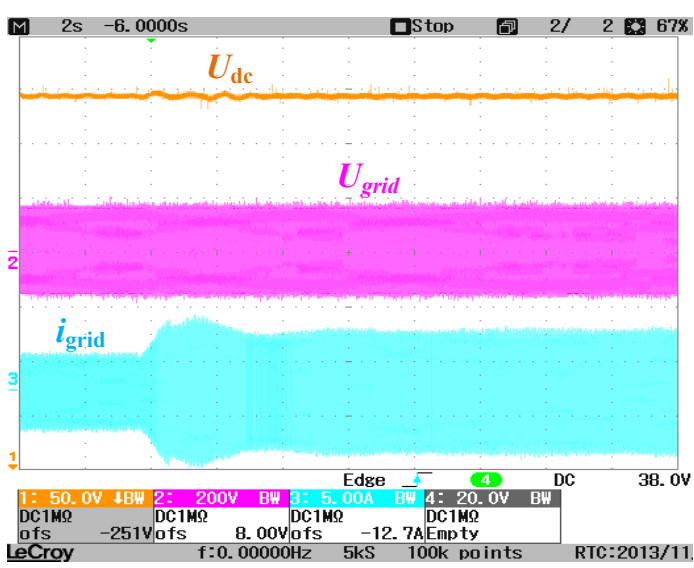

Fig. 20. Response for step change of speed with APFF. From top: dc-link voltage $\left(U_{d c}\right)$, grid voltage $\left(U_{\text {grid }}\right)$, grid current $\left(i_{\text {grid }}\right)$.

\section{CONCLUSION}

$\mathrm{AC} / \mathrm{DC} / \mathrm{AC}$ converters recently turned attention for small wind turbine (SWT) applications. Relatively simple control algorithm for the single-phase $\mathrm{DC} / \mathrm{AC}$ part of converter allows to precisely eliminate higher order harmonic distortion in the grid current. Two possible control schemes for the AC/DC part of converter (DTC-SVM and IRFOC) working with a PMSG are also investigated giving good dynamic response and sensorless operation. Further improvement can be provided with active power feed-forward (APFF) term added to the control system. Experimental validation proved the feasibility of simplified multilevel converter in SWT. Presented system is an interesting alternative for low cost fully controlled AC-DCAC converters applied to small power generator systems working with permanent magnet synchronous or induction generators interfacing to the single phase grid.

\section{ACKNOWLEDGMENT}

Described problems are a part of the project number 6511/B/T01/2011/40 "Research and development of a simplified three level AC/DC/AC diode clamped converter topology dedicated for use in wind energy applications" funded by National Science Center.

\section{REFERENCES}

[1] H. W. Van Der Broeck and J. D. Van Wyk, "A Comparative Investigation of a Three-Phase Induction Machine Drive with a Component Minimized Voltage-Fed Inverter under Different Control Options," IEEE Transactions on Industry Applications, vol. IA-20, no. 2, pp. 309-320, Mar. 1984.

[2] C. B. Jacobina, E. R. C. da Silva, A. M. N. Lima, and R. L. A. Ribeiro, "Vector and scalar control of a four switch three phase inverter," in Conference Record of the 1995 IEEE Industry Applications Conference Thirtieth IAS Annual Meeting, 1995, vol. 3, pp. 2422-2429.

[3] F. Blaabjerg, D. O. Neacsu, and J. K. Pedersen, "Adaptive SVM to compensate DC-link voltage ripple for four-switch three-phase voltagesource inverters," IEEE Transactions on Power Electronics, vol. 14, no. 4, pp. 743-752, Jul. 1999.

[4] E. C. dos Santos, E. R. C. da Silva, and A. A. M. Bento, "AC-DC-AC Power Converters with Novel Approach to Power Factor Correction in Three-Phase Systems," in Proceedings of 24th Annual IEEE Applied Power Electronics Conference and Exposition, 2009, pp. 677-682.

[5] "Vicontech Power Modules Catalog 2013/14," 2014. [Online]. Available: www.vicontech.com . [Accessed: 05-Mar-2014].

[6] B.-R. Lin and T.-C. Wei, "Space vector modulation strategy for an eightswitch three-phase NPC converter," IEEE Transactions on Aerospace and Electronic Systems, vol. 40, no. 2, pp. 553-566, Apr. 2004.

[7] J. I. Leon, R. Portillo, S. Vazquez, J. J. Padilla, L. G. Franquelo, and J. M. Carrasco, "Simple Unified Approach to Develop a Time-Domain
Modulation Strategy for Single-Phase Multilevel Converters," IEEE Transactions on Industrial Electronics, vol. 55, no. 9, pp. 3239-3248, Sep. 2008 .

[8] Y. Sato, T. Ishizuka, K. Nezu, and T. Kataoka, "A new control strategy for voltage-type PWM rectifiers to realize zero steady-state control error in input current," IEEE Transactions on Industry Applications, vol. 34, no. 3, pp. 480-486, 1998.

[9] R. Teodorescu, F. Blaabjerg, M. Liserre, and P. C. Loh, "A New Breed of Proportional-Resonant Controllers and Filters For Grid-Connected Voltage-Source Converters," IEE Proceedings on Electric Power Applications, vol. 153, no. 5, pp. 750-762, 2006.

[10] A. Maknouninejad, M. G. Simoes, and M. Zolot, "Single phase and three phase P+Resonant based grid connected inverters with reactive power and harmonic compensation capabilities," in Proceedings of International Electric Machines and Drives Conference, 2009, pp. 385-391.

[11] D. Swierczwsk, M. P. Kazmierkowski, and F. Blaabjerg, "DSP based direct torque control of permanent magnet synchronous motor (PMSM) using space vector modulation (DTC-SVM)," in Proceedings of the IEEE International Symposium on Industrial Electronics ISIE-02, 2002, pp. $723-727$ vol.3.

[12] W.-S. Chien and Y.-Y. Tzou, "Analysis and design on the reduction of DC-link electrolytic capacitor for $\mathrm{AC} / \mathrm{DC} / \mathrm{AC}$ converter applied to $\mathrm{AC}$ motor drives," in PESC 98 Record. 29th Annual IEEE Power Electronics Specialists Conference (Cat. No.98CH36196), vol. 1, pp. 275-279.

[13] S. Styński, PhD Thesis "Analysis and Control of Multilevel AC-DC-AC Flying Capacitor Converter Fed from Single-Phase Grid," Warsaw University of Technology, 2011.

[14] R. M. Tallam, R. Naik, M. L. Gasperi, and T. A. Nondahl, "Practical issues in the design of active rectifiers for AC drives with reduced DClink capacitance," in 38th IAS Annual Meeting on Conference Record of the Industry Applications Conference, vol. 3, pp. 1538-1545.

[15] M. Jasinski, D. Swierczynski, and M. P. Kazmierkowski, "Direct Active and Reactive Power Control of AC/DC/AC Converter with Permanent Magnet Synchronous Generator for Sea Wave Converter," in Proceedings of International Conference on Power Engineering, Energy and Electrical Drives, 2007, pp. 78-83.

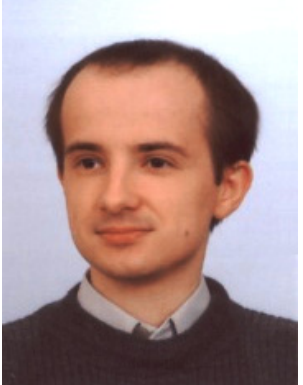

Pawel Mlodzikowski received a M.Sc. EE degree from Kazimierz Pulaski University of Technology and Humanities in Radom (Poland), Faculty of Transport and Electrical Engineeringin 2008. Since then a PhD student at Institute of Control and Industrial Electronics WUT.

Postal address: Warsaw University of Technology, Institute of Control and Industrial Electronics, Koszykowa str. 75, 00-662 Warsaw, Poland.

E-mail: pawel.mlodzikowski@ee.pw.edu.pl

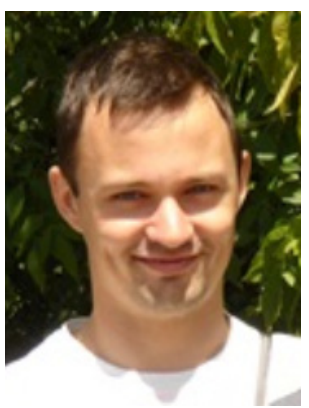

Adam Milczarek in 2005-2010 studied at Electrical Engineering Faculty of Warsaw University of Technology. Since 2011 Ph.D. student in Institute of Control and Industrial Electronics WUT.

Postal address: Warsaw University of Technology, Institute of Control and Industrial Electronics, Koszykowa str. 75, 00-662 Warsaw, Poland.

\section{E-mail: adam.milczarek@ee.pw.edu.pl}

Mariusz Malinowski received the Ph.D. and D.Sc. degrees in electrical engineering from the Institute of Control and Industrial Electronics, Warsaw University of Techno-logy (WUT), Poland, in 2001 and 2012, respectively. He has authored more than 130 technical papers. He is the holder of two implemented patents. He received IEEE IES David Irwin Early Career Award for "Outstanding research and development of modulation and control for industrial electronics converters" in 2011.

Postal address: Warsaw University of Technology, Institute of Control and Industrial Electronics, Koszykowa str. 75, 00-662 Warsaw, Poland.

E-mail: malin@ee.pw.edu.pl 